\title{
Respiratory Motor Recovery after Unilateral Spinal Cord Injury: Eliminating Crossed Phrenic Activity Decreases Tidal Volume and Increases Contralateral Respiratory Motor Output
}

\author{
Francis J. Golder, ${ }^{1}$ David D. Fuller, ${ }^{3}$ Paul W. Davenport, ${ }^{1}$ Richard D. Johnson, ${ }^{1}$ Paul J. Reier, ${ }^{2}$ and Donald C. Bolser ${ }^{1}$ \\ ${ }^{1}$ Department of Physiological Sciences, College of Veterinary Medicine, and ${ }^{2}$ Department of Neuroscience, College of Medicine, University of Florida, \\ Gainesville, Florida 32610, and ${ }^{3}$ Department of Comparative Biosciences, College of Veterinary Medicine, University of Wisconsin, Madison Wisconsin \\ 53706
}

By 2 months after unilateral cervical spinal cord injury (SCI), respiratory motor output resumes in the previously quiescent phrenic nerve. This activity is derived from bulbospinal pathways that cross the spinal midline caudal to the lesion (crossed phrenic pathways). To determine whether crossed phrenic pathways contribute to tidal volume in spinally injured rats, spontaneous breathing was measured in anesthetized $\mathrm{C}_{2}$ hemisected rats at 2 months after injury with an intact ipsilateral phrenic nerve, or with ipsilateral phrenicotomy performed at the time of the SCI (i.e., crossed phrenic pathways rendered ineffective) (dual injury). Ipsilateral phrenicotomy did not alter the rapid shallow eupneic breathing pattern in $\mathrm{C}_{2}$ injured rats. However, the ability to generate large inspiratory volumes after either vagotomy or during augmented breaths was impaired if crossed phrenic activity was abolished. We also investigated whether compensatory plasticity in contralateral motoneurons would be affected by eliminating crossed phrenic activity. Thus, contralateral phrenic motor output was recorded in anesthetized, vagotomized, and mechanically ventilated rats with dual injury during chemoreceptor stimulation. Hypercapnia, hypoxia, and asphyxia increased contralateral phrenic burst amplitude in the dual injury group more than in rats with SCI alone. Dual injury rats also had elevated baseline burst frequency. Together, these results demonstrate a functional role of crossed phrenic activity after SCI. Moreover, by preventing ipsilateral phrenic motor recovery in rats with unilateral SCI, segmental and supraspinal changes could be induced in contralateral respiratory motor output beyond that seen with SCI alone.

Key words: breathing; hemisection; hypercapnia; hypoxia; plasticity; rats; ventilation

\section{Introduction}

The crossed phrenic phenomenon (CPP) is a striking example of how existing, but normally ineffective, neural pathways can be recruited to promote motor recovery after a unilateral spinal cord injury (SCI). The CPP particularly applies to $\mathrm{C}_{2}$ hemisection, which severs bulbospinal inputs to ipsilateral phrenic motoneurons resulting in an electrically silent phrenic nerve and diaphragm on the side of the lesion (Goshgarian, 1979, 1981). Between 1 and 2 months after injury, some inspiratory activity resumes in the affected phrenic nerve and diaphragm without overt evidence for regeneration of the interrupted descending premotor fibers (Nantwi et al., 1999; Golder et al., 2001a). Goshgarian and colleagues (1991) have shown that some bulbospinal phrenic pathways in rats cross the spinal midline caudal to $\mathrm{C}_{2}$. It thus has been proposed that these crossed pathways represent the

\footnotetext{
Received 0ct. 29, 2002; revised Dec. 26, 2002; accepted Jan. 2, 2003.

This work was supported by the State of Florida Brain and Spinal Cord Injury Rehabilitation Trust Fund (F.J.G.), the Mark F. Overstreet Fund for Spinal Cord Regeneration Research (P.J.R.), and National Institutes of Health Grant P0I-NS-35702 (D.C.B., P.J.R.). We thank Melanie Rose, Julie Hammond, and Michael Wood for technical assistance, and Dr. Gordon Mitchell for comments on this manuscript.

Correspondence should be addressed to Francis J. Golder, Department of Comparative Biosciences, College of Veterinary Medicine, 2015 Linden Drive, Madison WI 53706. E-mail: golderf@svm.vetmed.wisc.edu. Copyright $\odot 2003$ Society for Neuroscience $\quad 0270-6474 / 03 / 232494-08 \$ 15.00 / 0$
}

"anatomical substrate" for the CPP (Goshgarian et al., 1991) (see Fig. 1).

Before the CPP is spontaneously expressed, ineffective crossed phrenic pathways can be activated chemically or pharmacologically (e.g., by hypercapnia or exogenous serotonin administration) (Goshgarian, 1979, 1981; Nantwi et al., 1996; Zhou and Goshgarian, 2000). As such, the CPP represents an intriguing model of intrinsic motor recovery from SCI that can be manipulated in onset and magnitude. Yet the functional significance of the CPP to breathing remains unknown. To address this issue, we compared rats with $\mathrm{C}_{2}$ hemisection alone or $\mathrm{C}_{2}$ hemisection plus ipsilateral phrenicotomy (i.e., preventing crossed phrenicmediated ipsilateral motor output to the diaphragm) (see Fig. 1). In this way, contribution of crossed phrenic pathways to ventilation and the control of breathing could be assessed. We hypothesized that crossed motor recovery in the ipsilateral phrenic nerve contributes to tidal volume in spontaneously breathing $\mathrm{C}_{2}$ injured rats.

After unilateral SCI, plasticity also is observed in contralateral motoneuron pools. For example, spinally hemisected chicks regain posture and locomotor skills via increased reliance on contralateral motor activity (Muir et al., 1998), which also contributes to altered locomotor patterns in rats with similar lesions (Webb and Muir, 2002). Plasticity in contralateral respiratory 
motor output has been observed recently in rats with $\mathrm{C}_{2}$ hemisection (Golder et al., 2001a). Specifically, the increase in phrenic motor output during hypercapnia was diminished from the uninjured side. This effect appeared to coincide with the onset of crossed phrenic activity. We reasoned that if crossed phrenic pathways make a significant contribution to respiratory motor control, then preventing CPP-related activity may lead to additional compensatory plasticity being evoked from contralateral phrenic motoneurons. Thus, we tested whether the combination of $\mathrm{C}_{2}$ hemisection with ipsilateral phrenicotomy would augment contralateral phrenic inspiratory motor output at baseline and during chemical challenge.

Portions of these data have been published previously (Golder et al., 2002).

\section{Materials and Methods}

Animals. Forty specific pathogen-free female rats (Harlan Sprague Dawley, Indianapolis, IN) from colony K63317 ranging in weight from 225 to $316 \mathrm{gm}$ and of similar age were used in this study. Animals were divided into normal $(n=6), C_{2}$ hemisection $(n=9), C_{2}$ hemisection shamoperated $(n=6)$, unilateral phrenicotomy $(n=7), \mathrm{C}_{2}$ hemisection plus thoracotomy (i.e., sham for phrenicotomy) $(n=6)$, and combined $\mathrm{C}_{2}$ hemisection plus ipsilateral phrenicotomy (dual injury) $(n=8)$ groups. All animals were evaluated at 2 months after injury. The initial experiment was designed to assess the pattern of spontaneous breathing in anesthetized animals. In the second experiment, phrenic neurograms were recorded in the same rats on the same experimental day. Animal husbandry and all procedures were in compliance with the Institutional Animal Care and Use Committee at the University of Florida.

Spinal cord hemisection. Rats were anesthetized with medetomidine (75 $\mu \mathrm{g} / \mathrm{kg}, \mathrm{i} . \mathrm{m}$.) and isoflurane in oxygen. After orotracheal intubation, anesthesia was maintained with isoflurane in oxygen, and rats were ventilated mechanically. A laminectomy was made at the second cervical vertebral level exposing the second cervical spinal segment. A 1-mm-long left-sided hemisection was made in the cranial segment of $\mathrm{C}_{2}$, and the section was aspirated with a fine-tipped glass pipette. The dura and arachnoid were closed with 10-0 suture. All animals were allowed to recover and received atipamezole $(0.1 \mathrm{mg} / \mathrm{kg}$, i.v. $)$ to antagonize the anesthetic effects of medetomidine. Buprenorphine (50 $\mu \mathrm{g} / \mathrm{kg}$, i.v.) and carprofen $(5 \mathrm{mg} / \mathrm{kg}$, i.v.) were administered for postsurgical pain control. Analgesics were repeated as required over the next $2 \mathrm{~d}$. The sham operation procedure was the same, but the spinal cord was left intact after the meninges were incised and sutured.

Unilateral phrenicotomy. During similar anesthetic conditions as above, a $1.5-\mathrm{cm}$-long left lateral thoracotomy was made between the eighth and ninth rib adjacent to the costochondral junction. Elevation of the left caudal lung lobe allowed the left phrenic nerve to be visualized running in a craniocaudal direction adjacent to the caudal vena cava. A $1.2-1.5 \mathrm{~cm}$ segment of the phrenic nerve was removed using a surgical hook and microscissors. Phrenicotomy occurred before the nerve arborizing to supply the ipsilateral diaphragm. Lidocaine $(4 \mathrm{mg} / \mathrm{kg}$ total dose, $2 \%$ solution) was injected into the intercostal muscles dorsal to the thoracotomy incision, and the wound was sutured. All animals received postoperative care as described above. For the sham-operated group, the procedure was the same, but the phrenic nerve was left intact after the left caudal lung lobe was elevated. The rats that received both $\mathrm{C}_{2}$ hemisection and ipsilateral phrenicotomy had their injuries performed under the same anesthetic.

Spontaneous breathing measurements. After a 2 month postsurgical period, anesthesia was induced with isoflurane in oxygen via an induction chamber. A catheter was then placed in the lateral tail vein, and urethane $(1.5 \mathrm{gm} / \mathrm{kg}$, i.v.) was administered slowly while the isoflurane was discontinued. Anesthesia was maintained by administering urethane $(0.2-0.3 \mathrm{gm} / \mathrm{kg}$, i.v. $)$ as needed. A catheter was placed in a femoral artery to allow monitoring of direct arterial blood pressure and to allow collection of arterial blood $(0.15 \mathrm{ml})$ for blood gas analysis (iSTAT, Waukesha, WI). A femoral vein catheter was placed to administer drugs and fluids.
Atropine sulfate $(0.2 \mathrm{mg} / \mathrm{kg}$, i.v. $)$ was administered to decrease upper respiratory secretions. The trachea was cannulated at the midcervical level, and rats were allowed to breathe spontaneously. Rectal temperature was maintained at $38.0 \pm 0.5^{\circ} \mathrm{C}$ with an electric heating pad. All blood gas measurements were corrected to the rectal temperature at the time of sampling. When surgical preparation was completed, rats were placed in a supine position, and a pneumotachometer (Hans Rudolf Inc., Kansas City, MO) was attached to the tracheal cannula. The pneumotachometer was calibrated using a square wave pulse of known volume and duration. Airflow was recorded using a differential pressure transducer (model MP45-14-871, Validyne, Northridge, CA) attached to the pneumotachometer. Airflow was electronically integrated to derive volume. Each breath phase (inspiration and expiration) was integrated separately, providing continuous display of both inspiratory volume and expiratory volume.

After the pneumotachometer was attached to the tracheotomy tube, rats were allowed to breathe room air for $30 \mathrm{~min}$ before baseline data were obtained. Inspired oxygen fraction was then increased from 0.21 to 0.40 (balance nitrogen) by using an open system (delivering $>2.01 / \mathrm{min}$ ) covering the pneumotachometer port. The $\mathrm{Fi}_{\mathrm{O}_{2}}$ was increased to minimize the influence of carotid body stimulation (Vidruk et al., 2001) on respiratory drive. Data were collected $10 \mathrm{~min}$ after inspired oxygen fraction was increased. The vagi were then isolated in the midcervical region and cut, and airflow was recorded $10 \mathrm{~min}$ after vagotomy. Arterial blood was sampled after each recording and was replaced by $0.4 \mathrm{ml}$ of $0.9 \%$ saline intravenously.

Arterial blood pressure, inspiratory and expiratory airflow, and inspired and tidal volume were recorded on chart paper and VCR tape. Data were digitized on-line by a computer-based data analysis system (CED 1401, Cambridge, UK). Tidal volume was measured as the peak integrated expiratory volume and averaged over five consecutive breaths immediately before the arterial blood sample. Respiratory rate was calculated from the respiratory cycle time. Expired minute volume was calculated as the product of tidal volume and respiratory rate. Both tidal and minute volumes were indexed to body weight.

Measurement of respiratory motor output. After the pattern of spontaneous breathing was measured, phrenic neurograms were recorded from all rats. Animals were ventilated mechanically $\left(\mathrm{Fi}_{\mathrm{O}_{2}}=0.40\right)$ (Harvard small animal ventilator) and paralyzed with pancuronium $(1.0 \mathrm{mg} / \mathrm{kg}$, i.v.). The phrenic nerves were dissected within the caudal neck region (before the communication with the accessory phrenic nerve) using a ventral approach. As such, recordings were made proximal to the site of phrenicotomy. The nerves were cut distally and placed over bipolar silver recording electrodes and covered in a mixture of paraffin and mineral oil. Tidal volume was set at $2-2.5 \mathrm{ml}$.

Baseline conditions were standardized among groups by setting the $\mathrm{Pa}_{\mathrm{CO}_{2}}$ at $3 \mathrm{mmHg}$ above the apneic threshold. Apnea was accomplished by increasing the ventilator rate while monitoring the end-tidal $\mathrm{P}_{\mathrm{CO}_{2}}$ with a mainstream $\mathrm{CO}_{2}$ monitor (Capnoguard, Novametrix Medical Systems, Wallingford, CT). The apneic threshold was defined as the end-tidal $\mathrm{P}_{\mathrm{CO}_{2}}$ mid-point between the cessation of bursting and its reappearance once the ventilator rate was decreased. The end-tidal to arterial difference in $\mathrm{P}_{\mathrm{CO}_{2}}$ was measured via an arterial blood sample. This difference was used to calculate the arterial $\mathrm{P}_{\mathrm{CO}_{2}}$ at apnea. Rats were allowed $15 \mathrm{~min}$ at their baseline $\mathrm{P}_{\mathrm{CO}_{2}}$ before the protocol was started.

Stable baseline neurograms were recorded while the animal was ventilated with a hyperoxic gas mixture $\left(\mathrm{Fi}_{\mathrm{O}_{2}}=0.40 ; \mathrm{Fi}_{\mathrm{CO}_{2}}=0.00 ; \mathrm{Fi}_{\mathrm{N}_{2}}=\right.$ $0.60)$. Animals were then challenged with $5 \mathrm{~min}$ of hypercapnia $\left(\mathrm{Fi}_{\mathrm{O}_{2}}=\right.$ $\left.0.40 ; \mathrm{Fi}_{\mathrm{CO}_{2}}=0.05 ; \mathrm{Fi}_{\mathrm{N}_{2}}=0.55\right)$ and $2 \mathrm{~min}$ of hypoxia $\left(\mathrm{Fi}_{\mathrm{O}_{2}}=0.08\right.$; $\mathrm{Fi}_{\mathrm{CO}_{2}}=0 ; \mathrm{Fi}_{\mathrm{N}_{2}}=0.92$ ), separated by at least $5 \mathrm{~min}$ of hyperoxia. Before returning to baseline conditions, an arterial blood sample was taken to measure blood gases. A final challenge of asphyxia was induced by terminating mechanical ventilation until the animal became apneic. The raw neurograms were amplified, filtered $(0.2-2.0 \mathrm{kHz})$, recorded on VCR tape, and streamed on-line to a computer-based data analysis system (CED 1401).

Off-line analysis included evaluating the rectified and moving averaged neurograms from the ipsilateral phrenic nerve for the presence of crossed phrenic activity. Neurograms were inspected at an end-tidal $\mathrm{P}_{\mathrm{CO}_{2}}$ 
that was equivalent to the $\mathrm{Pa}_{\mathrm{CO}_{2}}$ for that animal during spontaneous ventilation. Inspiratory bursting was identified by the presence of phasic activity in an amplified audio record of the raw neurogram signal and the moving averaged rectified neurogram. Functional recovery was considered present if ipsilateral phrenic phasic bursting, identified by either method, was in synchrony with inspiratory activity in the contralateral phrenic neurogram.

Additional off-line analysis included measuring phrenic burst frequency (i.e., respiratory rate) and rectified and moving averaged amplitude from the phrenic neurogram on the uninjured side during baseline conditions, hypercapnia, and hypoxia. Baseline burst frequency and amplitude were measured over $60 \mathrm{sec}$ and 10 bursts, respectively. During hypercapnia, burst frequency and amplitude were averaged from five adjacent bursts at the $5 \mathrm{~min}$ end point before blood gas sampling. During hypoxia the measurements were taken at $120 \mathrm{sec}$. Asphyxic maximal amplitude was measured from the largest burst characterized as eupneiclike using the criteria of St. John and Paton (2000). Changes in amplitude were expressed as a percentage of baseline values.

Postmortem observations and histological confirmation of $\mathrm{C}_{2}$ hemisection. All spinally hemisected rats were exsanguinated and transcardially perfused with $4 \%$ paraformaldehyde solution in PBS. The pleural cavity was examined before perfusion for evidence of gross lung consolidation, pleural adhesions, or scarring of the intercostal space at the thoracotomy site. In addition, the position of the proximal stump of the injured phrenic nerve was noted. The cervical spinal cord was removed, and the $\mathrm{C}_{2}$ spinal segment was sectioned at $40 \mu \mathrm{m}$ thickness and stained with cresyl violet. The extent of cervical spinal cord injury was assessed under light microscopy.

Data analysis. All values are expressed as mean \pm SE. Normality of the data and equivalency of variance were confirmed before parametric analysis was used. Nonparametric means were compared using the KruskalWallis ANOVA followed by Mann-Whitney $U$ tests when indicated. All other means were compared using repeated measures ANOVA. Multiple comparisons across groups were made using the Student-NewmanKeuls test. Paired means were compared using either Wilcoxon matched pairs test or paired Student's $t$ tests, where appropriate. Differences were considered significant when $p<0.05$.

\section{Results}

\section{Postmortem observations and histological confirmation of}

\section{$\mathrm{C}_{2}$ hemisection}

The projections of bulbospinal pathways to the ipsilateral phrenic motoneurons are widely distributed, and thus interruption of all descending respiratory projections requires complete removal of both the lateral and ventral funiculi (Lipski et al., 1994). With use of these criteria, histological examination confirmed complete hemisection in all $\mathrm{C}_{2}$ injured rats without overt damage to the contralateral spinal cord. Figures of representative $\mathrm{C}_{2}$ hemisections from our laboratory have been published previously (Golder et al., 2001a,b).

The thoracic cavity of all rats was examined postmortem to identify gross pulmonary or chest wall pathology. A small adhesion between the left caudal lung lobe and left thoracic wall was present in one $\mathrm{C}_{2}$ hemisection plus phrenicotomy rat. In all rats that received a thoracotomy, mild scaring was present between the eighth and ninth rib, but this was restricted to the site of incision. The proximal stump of the sectioned phrenic nerve was located within the mediastinum at the level of the heart base in all phrenicotomized rats. In addition, the ipsilateral diaphragm was noticeably thinner and translucent in phrenicotomized rats compared with the contralateral side. No visible differences between ipsilateral and contralateral diaphragms were seen in rats with $\mathrm{C}_{2}$ hemisection alone (Fig. 1).

\section{Spontaneous breathing in vagally intact rats}

The initial experiment evaluated the pattern of spontaneous room air breathing. No differences in tidal or minute volumes,

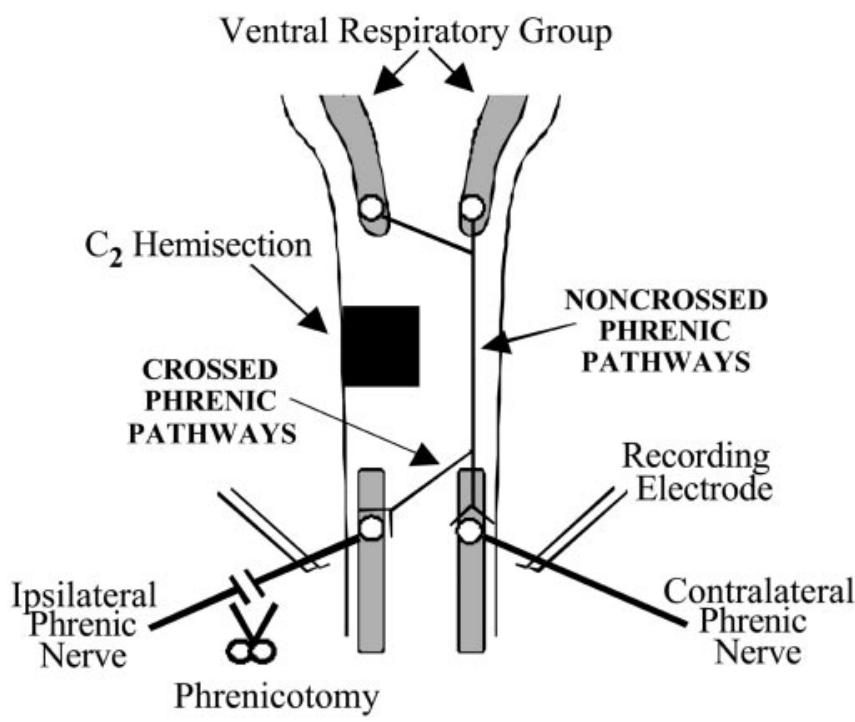

Figure 1. A schematic depicting the location of each injury and recording sites. $C_{2}$ hemisection interrupts bulbospinal projections of premotor neurons in the ventral respiratory group (medulla) to the phrenic nucleus ipsilateral to injury. Some premotor neurons or other pathways, or both, cross the midline in the cervical spinal cord and reestablish inspiratory motor drive to the ipsilateral diaphragm (CROSSED PHRENIC PATHWAYS) by 2 months after injury. Phrenicotomy on the side of injury prevents this crossed phrenic activity from reaching the diaphragm.

respiratory rate, cardiovascular, or arterial blood gas measurements were detected between normal and $\mathrm{C}_{2}$ hemisection shamoperated rats. Therefore, these groups were subsequently combined as one control group. In addition, there were no differences between $\mathrm{C}_{2}$ hemisection-only and $\mathrm{C}_{2}$ injured rats with a thoracotomy; these rats are also represented by one $\mathrm{C}_{2}$ hemisection group.

No significant differences existed in body mass among controls $(278 \pm 24 \mathrm{gm}), \mathrm{C}_{2}$ hemisection $(268 \pm 16 \mathrm{gm})$, phrenicotomy ( $286 \pm 8 \mathrm{gm})$, and combined injury (266 $\pm 17 \mathrm{gm})$ groups. In addition, rectal temperature was similar across groups and did not change throughout the protocol. Mean blood pressure also was not affected by injury (Table 1).

Consistent with previous studies (Rocco et al., 1997; Golder et al., 2001b), $C_{2}$ hemisection and phrenicotomy, as single injuries, altered the pattern of breathing on room air. Both injuries decreased tidal volume $(p<0.001)$ (Table 2$)$ and increased respiratory rate $(p<0.01)$ (Table 2$)$. Changes in tidal volume and rate were similar between these injuries. Minute ventilation was not altered after phrenicotomy but was lower than controls in the $\mathrm{C}_{2}$ hemisection-only group $(p<0.05$ ) (Table 2$)$. The single injuries did not alter arterial $\mathrm{pH}$ or $\mathrm{P}_{\mathrm{CO}_{2}}$ (Table 1); however, $\mathrm{Pa}_{\mathrm{O}_{2}}$ decreased $(p<0.05)$ (Table 1$)$.

Sectioning the phrenic nerve ipsilateral to $C_{2}$ injury did not significantly alter the pattern of breathing or minute volume relative to SCI alone (Table 2). However, there was a trend for tidal volume to be lower in the dual injury group compared with $\mathrm{C}_{2}$ hemisection rats $(p=0.08)$. Conversely, when compared with rats with a phrenicotomy alone, the addition of a $C_{2}$ hemisection significantly decreased tidal volume $(p<0.01)$ (Table 2$)$. Arterial $\mathrm{pH}$ was lower in rats with dual injury than in all other groups (Table 1$)(p<0.05)$. However, the acidosis was not of respiratory origin because arterial $\mathrm{P}_{\mathrm{CO}_{2}}$ did not change (Table 1).

Because $\mathrm{Pa}_{\mathrm{O}_{2}}$ was lower than controls after injury, rats were allowed to breathe oxygen-enriched air to increase arterial oxy- 
Table 1. Arterial blood gas and mean arterial blood pressure measurements from control, $C_{2}$ hemisection, phrenicotomy, and dual injury $\left(C_{2}\right.$ hemisection and ipsilateral phrenicotomy) groups

\begin{tabular}{|c|c|c|c|c|c|c|}
\hline & Vagus & $\mathrm{Fi}_{\mathrm{O}_{2}}$ & Control & $\mathrm{C}_{2}$ hemisection & Phrenicotomy & Dual injury \\
\hline \multirow[t]{3}{*}{$\mathrm{pH}$} & Intact & 0.21 & $7.38 \pm 0.01$ & $7.36 \pm 0.01$ & $7.36 \pm 0.01$ & $7.31 \pm 0.01^{* \dagger \neq}$ \\
\hline & Intact & 0.40 & $7.35 \pm 0.01^{a}$ & $7.33 \pm 0.01^{a}$ & $7.31 \pm 0.01^{a}$ & $7.28 \pm 0.01^{a * t+}$ \\
\hline & Cut & 0.40 & $7.36 \pm 0.01$ & $7.33 \pm 0.01$ & $7.31 \pm 0.01^{*}$ & $7.30 \pm 0.01^{* \ddagger}$ \\
\hline \multirow[t]{3}{*}{$\mathrm{Pa}_{\mathrm{CO}_{2}}(\mathrm{mmHg})$} & Intact & 0.21 & $47 \pm 1$ & $48 \pm 1$ & $45 \pm 2$ & $49 \pm 2$ \\
\hline & Intact & 0.40 & $50 \pm 1^{a}$ & $53 \pm 1^{a}$ & $51 \pm 2^{a}$ & $52 \pm 2^{a}$ \\
\hline & Cut & 0.40 & $48 \pm 1$ & $50 \pm 1$ & $50 \pm 2$ & $53 \pm 2$ \\
\hline \multirow[t]{3}{*}{$\mathrm{Pa}_{\mathrm{O}_{2}}(\mathrm{mmHg})$} & Intact & 0.21 & $90 \pm 3$ & $80 \pm 3^{*}$ & $81 \pm 5^{*}$ & $74 \pm 4^{*}$ \\
\hline & Intact & 0.40 & $176 \pm 3^{a}$ & $162 \pm 3^{a *}$ & $157 \pm 5^{a *}$ & $150 \pm 4^{a *}$ \\
\hline & Cut & 0.40 & $177 \pm 4$ & $165 \pm 4^{*}$ & $158 \pm 8^{*}$ & $162 \pm 4^{*}$ \\
\hline \multirow[t]{3}{*}{$\mathrm{BP}(\mathrm{mmHg})$} & Intact & 0.21 & $113 \pm 2$ & $123 \pm 1$ & $111 \pm 2$ & $115 \pm 2$ \\
\hline & Intact & 0.40 & $119 \pm 2^{a}$ & $128 \pm 1^{a}$ & $126 \pm 2^{a}$ & $123 \pm 2^{a}$ \\
\hline & Cut & 0.40 & $115 \pm 3$ & $130 \pm 2$ & $136 \pm 3$ & $125 \pm 3$ \\
\hline
\end{tabular}

Measurements were obtained from anesthetized spontaneously breathing vagally intact rats (Intact) during room air breathing $\left(\mathrm{Fi}_{\mathrm{O}_{2}}=0.21\right)$, during oxygen supplementation ( $\left.\mathrm{Fi}_{02}=0.40\right)$, and after bilateral cervical vagotomy ( $\left(\mathrm{Cut}_{\mathrm{O}}\right)$. All values are mean \pm SE. BP, Mean arterial blood pressure; ${ }^{*} p<0.05$ relative to controls; ${ }^{\dagger} p<0.05$ relative to phrenicotomy; ${ }^{\ddagger} p<0.05$ relative to $\mathrm{C}_{2}$ hemisection; ${ }^{a} p<0.05$ relative to room air value.

Table 2. Pattern of breathing and minute volume from control, $C_{2}$ hemisection, phrenicotomy, and dual injury $\left(C_{2}\right.$ hemisection and ipsilateral phrenicotomy) groups

\begin{tabular}{|c|c|c|c|c|c|c|}
\hline & Vagus & $\mathrm{Fi}_{\mathrm{O}_{2}}$ & Control & $\mathrm{C}_{2}$ hemisection & Phrenicotomy & Dual injury \\
\hline \multirow[t]{3}{*}{ Tidal volume (ml/kg) } & Intact & 0.21 & $8.3 \pm 0.2$ & $6.1 \pm 0.1^{*}$ & $6.4 \pm 0.3^{*}$ & $5.6 \pm 0.2^{* \dagger}$ \\
\hline & Intact & 0.40 & $7.8 \pm 0.2^{a}$ & $5.7 \pm 0.2^{a_{*}}$ & $6.2 \pm 0.2^{a_{*}}$ & $5.4 \pm 0.2^{a_{*} \dagger}$ \\
\hline & Cut & 0.40 & $14.0 \pm 1.3^{b}$ & $12.5 \pm 0.7^{b}$ & $13.0 \pm 1.2^{b}$ & $9.4 \pm 0.5^{b * \dagger \neq}$ \\
\hline \multirow[t]{3}{*}{$\operatorname{RR}\left(\min ^{-1}\right)$} & Intact & 0.21 & $126 \pm 6$ & $151 \pm 5^{*}$ & $163 \pm 5^{*}$ & $153 \pm 4^{*}$ \\
\hline & Intact & 0.40 & $119 \pm 6^{a}$ & $142 \pm 2^{a *}$ & $147 \pm 4^{a *}$ & $136 \pm 3^{a *}$ \\
\hline & Cut & 0.40 & $44 \pm 4^{b}$ & $38 \pm 3^{b}$ & $41 \pm 2^{b}$ & $45 \pm 3^{b}$ \\
\hline \multirow[t]{3}{*}{ Minute volume $\left(\mathrm{ml} \cdot \mathrm{kg}^{-1} \cdot \min ^{-1}\right)$} & Intact & 0.21 & $1037 \pm 36$ & $924 \pm 35^{* \dagger}$ & $1045 \pm 50$ & $849 \pm 23^{* \dagger}$ \\
\hline & Intact & 0.40 & $919 \pm 36^{a}$ & $813 \pm 30^{a_{* \dagger}}$ & $906 \pm 44^{a}$ & $729 \pm 32^{a_{* \dagger}}$ \\
\hline & Cut & 0.40 & $578 \pm 23^{b}$ & $459 \pm 29^{b_{*}}$ & $533 \pm 57^{b}$ & $415 \pm 24^{b_{*}}$ \\
\hline Sigh volume $(\mathrm{ml} / \mathrm{kg})$ & Intact & 0.21 & $24.3 \pm 1.6$ & $17.3 \pm 1.1^{*}$ & $16.5 \pm 0.5^{*}$ & $12.6 \pm 1.0^{* \dagger \neq}$ \\
\hline Sigh frequency $\left(\min ^{-1}\right)$ & Intact & 0.21 & $0.11 \pm 0.04$ & $0.35 \pm 0.07^{*}$ & $0.24 \pm 0.07$ & $0.39 \pm 0.09^{*}$ \\
\hline
\end{tabular}

Measurements were obtained from anesthetized spontaneously breathing vagally intact rats (Intact) during room air breathing $\left(\mathrm{Fi}_{\mathrm{O}_{2}}=0.21\right)$, during oxygen supplementation ( $\left.\mathrm{Fi}_{\mathrm{O}_{2}}=0.40\right)$, and after bilateral cervical vagotomy $(\mathrm{Cut})$. All values are mean \pm SE. RR, Respiratory rate; ${ }^{*} p<0.05$ relative to controls; ${ }^{\dagger} p<0.05$ relative to phrenicotomy; ${ }^{\ddagger} p<0.05$ relative to $\mathrm{C}_{2}$, hemisection; ${ }^{a} p<0.05$ relative to room air value; ${ }^{b} p<0.05$ relative to vagally intact state.

gen tension above $130 \mathrm{mmHg}$ (Table 1). Oxygen supplementation decreased respiratory drive in all groups as evidenced by decreased tidal volume, respiratory rate, and minute volume $(p<0.001)$ (Table 2) and increased $\mathrm{Pa}_{\mathrm{CO}_{2}}$ and decreased $\mathrm{pH}$ $(p<0.05)$ (Table 1). Although hyperoxia increased the mean $\mathrm{Pa}_{\mathrm{O}_{2}}$ above $150 \mathrm{mmHg}$ in all groups, the effect of each injury on the pattern of breathing was similar to that seen while breathing room air (Table 2).

Phrenicotomy in the spinal-injured group altered the pattern of augmented breaths (sighs) while rats were breathing room air. Augmented breaths are airway-protective reflexes characterized by large volumes. Sighs were identified on the basis of the criteria of Cherniack et al. (1981). During a sigh, inspired volume and airflow are biphasic; the initial phase resembles the preceding breath, and the second phase is characterized by greater airflow and volume. Spinal cord injury, with or without phrenicotomy, increased the frequency of augmented breaths compared with controls $(p<0.05)$ (Table 2$)$. In addition, either $C_{2}$ injury or phrenicotomy alone decreased the volume of augmented breaths compared with controls $(p<0.05)$ (Table 2$)$. This effect of injury on sigh volume reflects the lower tidal volume during eucapneic breathing, and a lower change in volume during a sigh compared with controls $(p<0.05)$ (Fig. $2 B$ ). The addition of ipsilateral phrenicotomy in $C_{2}$ injured rats further decreased sigh volume $(p<0.05)$ (Table 2$)$ and the change in volume from baseline values $(p<0.05)$ (Fig. $2 B$ ) below that seen in all other groups. Sighs were evaluated only during room air breathing because oxygen supplementation decreased their frequency such that statistical comparisons across groups were not possible.

\section{Change in Tidal Volume $(\mathrm{ml} / \mathrm{kg})$}

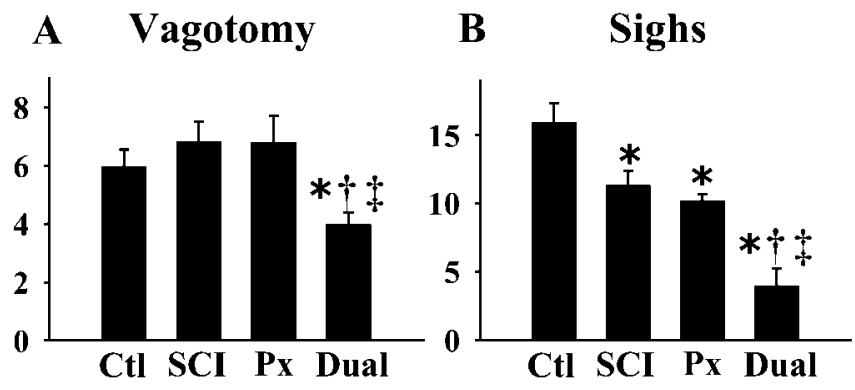

Figure 2. Change in tidal volume after bilateral vagotomy $(A)$ and during sighs $(B)$. Sigh volume was measured on room air and before vagotomy. Values were recorded from control $(C t l), C_{2}$ injured $(S C l)$, phrenicotomy $(P x)$, and combined $C_{2}$ injury and ipsilateral phrenicotomy (Dual) groups. ${ }^{*} p<0.05$ relative to controls; ${ }^{\dagger} p<0.05$ relative to phrenicotomy alone; ${ }^{\ddagger} p<$ 0.05 relative to $C_{2}$ hemisection alone.

\section{Spontaneous breathing in rats with bilateral vagotomy}

Both vagi were cut to test whether (1) an intact ipsilateral phrenic nerve in $\mathrm{C}_{2}$ injured rats provides functional benefit during conditions generating large inspiratory volumes and (2) vagal mechanisms contribute to the pattern of breathing after each injury. Bilateral vagotomy increased tidal volume $(p<0.001)$ (Table 2$)$ and decreased respiratory rate $(p<0.001)$ (Table 2$)$ in all groups. After these changes, tidal volume and frequency were no longer different between the single injury groups and controls (Table 2). Indeed, the single injury groups were capable of increasing tidal volume by a similar amount as controls (Fig. 2A). 
Table 3. Arterial blood gas and mean arterial blood pressure measurements from control, $C_{2}$ hemisection, phrenicotomy, and dual injury $\left(C_{2}\right.$ hemisection and ipsilateral phrenicotomy) groups

\begin{tabular}{|c|c|c|c|c|c|}
\hline & Condition & Control & $C_{2}$ hemisection & Phrenicotomy & Dual injury \\
\hline \multirow{3}{*}{$\mathrm{pH}$} & Baseline & $7.39 \pm 0.01$ & $7.40 \pm 0.01$ & $7.40 \pm 0.02$ & $7.40 \pm 0.01$ \\
\hline & Hypercapnia & $7.24 \pm 0.01$ & $7.24 \pm 0.01$ & $7.25 \pm 0.01$ & $7.24 \pm 0.01$ \\
\hline & Нypoxia & $7.38 \pm 0.01$ & $7.40 \pm 0.01$ & $7.40 \pm 0.02$ & $7.39 \pm 0.01$ \\
\hline \multirow{3}{*}{$\mathrm{Pa}_{\mathrm{CO}_{2}}(\mathrm{mmHg})$} & Baseline & $38 \pm 2$ & $37 \pm 1$ & $36 \pm 1$ & $37 \pm 1$ \\
\hline & Hypercapnia & $66 \pm 2$ & $64 \pm 1$ & $64 \pm 2$ & $64 \pm 2$ \\
\hline & Hypoxia & $37 \pm 1$ & $33 \pm 2$ & $33 \pm 2$ & $36 \pm 1$ \\
\hline \multirow[t]{3}{*}{$\mathrm{Pa}_{\mathrm{O}_{2}}(\mathrm{mmHg})$} & Baseline & $186 \pm 4$ & $166 \pm 4^{*}$ & $168 \pm 9^{*}$ & $166 \pm 6^{*}$ \\
\hline & Hypercapnia & $195 \pm 6$ & $172 \pm 4$ & $173 \pm 7$ & $173 \pm 5$ \\
\hline & Hypoxia & $26 \pm 2$ & $28 \pm 1$ & $27 \pm 2$ & $29 \pm 2$ \\
\hline \multirow[t]{3}{*}{$\mathrm{BP}(\mathrm{mmHg})$} & Baseline & $110 \pm 4$ & $119 \pm 4$ & $129 \pm 7$ & $120 \pm 4$ \\
\hline & Hypercapnia & $115 \pm 5$ & $123 \pm 3$ & $133 \pm 8$ & $128 \pm 5$ \\
\hline & Hypoxia & $94 \pm 8$ & $78 \pm 6$ & $101 \pm 9$ & $71 \pm 7$ \\
\hline
\end{tabular}

Measurements were obtained from anesthetized rats that were bilaterally vagotomized and mechanically ventilated with oxygen enriched air. All values are mean \pm SE. BP, Mean arterial blood pressure. ${ }^{*} p<0.05$ relative to controls.

In contrast, tidal volume in the rats with $\mathrm{C}_{2}$ hemisection plus phrenicotomy now was lower than all other groups $(p<0.05)$ (Table 2). This reflects a smaller change in tidal volume after vagotomy in the dual injury group $(p<0.05)$ (Fig. $2 A)$. Minute volume decreased in all groups after vagotomy $(p<0.05)$ and remained lower in $\mathrm{C}_{2}$ injured groups than controls (Table 2).

\section{Uncrossed phrenic motor output}

During the second series of experiments, we evaluated respiratory motor output from the contralateral phrenic nerve, which in $\mathrm{C}_{2}$ hemisected rats represents the contribution from uncrossed pathways (Fig. 1). The $\mathrm{Pa}_{\mathrm{CO}_{2}}$ at apneic threshold was not different among groups (controls: $35 \pm 2 \mathrm{mmHg}$; $\mathrm{C}_{2}$ hemisection: $34 \pm 1$ mmHg; phrenicotomy: $33 \pm 1 \mathrm{mmHg}$; and dual injury: $34 \pm 1$ $\mathrm{mmHg}$ ). Consistent with spontaneously breathing rats, $\mathrm{Pa}_{\mathrm{O}_{2}}$ was lower than controls after injury during baseline and hypercapnic conditions $(p<0.05)$ (Table 3). Beyond this difference, arterial blood gases and blood pressure were equivalent among the four groups (Table 3).

Consistent with our previous report (Golder et al., 2001a), contralateral phrenic inspiratory burst amplitude in rats with $\mathrm{C}_{2}$ hemisection was lower than controls only during hypercapnia, but not hypoxia or asphyxia (Fig. 3) $(p<0.05)$. However, this effect of injury was abolished by ipsilateral phrenicotomy (Fig. 3). Indeed, inspiratory motor output from the contralateral phrenic nerve in dual injury rats was significantly greater than all other groups during hypercapnia, hypoxia, and asphyxia (Fig. 3$)(p<$ 0.01 ). We additionally confirmed that this pattern was not specific to normalized data by comparing the raw neurogram voltages among groups (data not shown).

\section{Crossed phrenic motor output}

The ipsilateral phrenic neurogram was evaluated in this study to determine the incidence of crossed phrenic activity in the $\mathrm{C}_{2}$ injured groups. Although spontaneous recovery of inspiratory activity in this nerve has been reported previously (Nantwi et al., 1999; Golder et al., 2001a), identifying the presence of crossed motor output was important in interpreting the effect of phrenicotomy on tidal volume in spontaneously breathing rats. Phasic bursting was present in all control and phrenicotomy-only rats, 12 of 15 rats with $C_{2}$ injury alone ( $80 \%$ of rats), and no rats in the dual injury group (Fig. 4). Two $\mathrm{C}_{2}$ hemisection-only rats had audible evidence of crossed phrenic activity without visible bursts being present. When compared with the magnitude of inspiratory activity in the contralateral phrenic nerve, ipsilateral phrenic motor output was visibly reduced in amplitude in $\mathrm{C}_{2}$

\section{Contralateral Phrenic Amplitude (\% of baseline amplitude above baseline)}
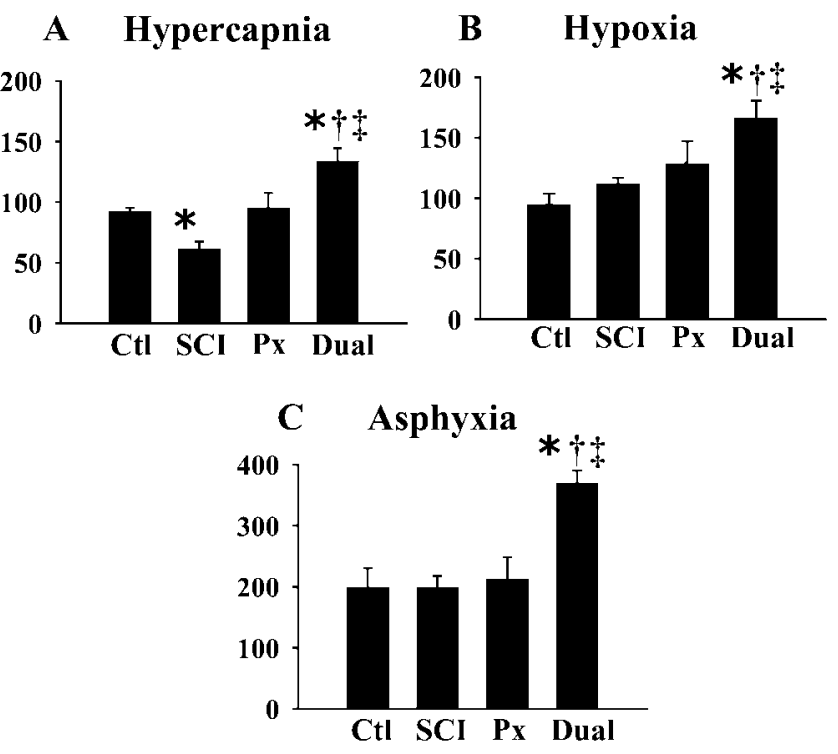

Figure 3. Respiratory motor output from the contralateral phrenic nerve as rectified, moving averaged amplitude expressed as percentage of baseline value above baseline. Measurements were obtained from control $(C t I), C_{2}$ injured $(S C l)$, phrenicotomy $(P x)$, and combined $C_{2}$ injury and ipsilateral phrenicotomy (Dual) groups. Measurements were taken during hypercapnic, hypoxic, and asphyxic recording conditions. ${ }^{*} p<0.05$ relative to controls; ${ }^{\dagger} p<0.05$ relative to phrenicotomy alone; ${ }^{\ddagger} p<0.05$ relative to $C_{2}$ hemisection alone.

hemisection-only and phrenicotomy-only rats. Although activity was absent during baseline conditions and hypercapnia in the dual injury group, six of these rats demonstrated some ipsilateral inspiratory bursting during either hypoxia or asphyxia.

\section{Phrenic burst frequency}

Supraspinal plasticity in the control of breathing after cervical SCI is evident from changes in phrenic burst frequency (Golder et al., 2001a). Burst frequency in the dual injury group was higher during baseline conditions than rats with $\mathrm{C}_{2}$ hemisection alone (Fig. 5) $(p<0.05)$. However, during hypercapnia all injury groups had greater burst frequency than control rats (Fig. 5) $(p<$ $0.05)$. An enhanced rate response in the dual injury group also was present during hypoxia (Fig. 5) $(p<0.05)$. The asphyxic period was not analyzed with respect to burst frequency because 

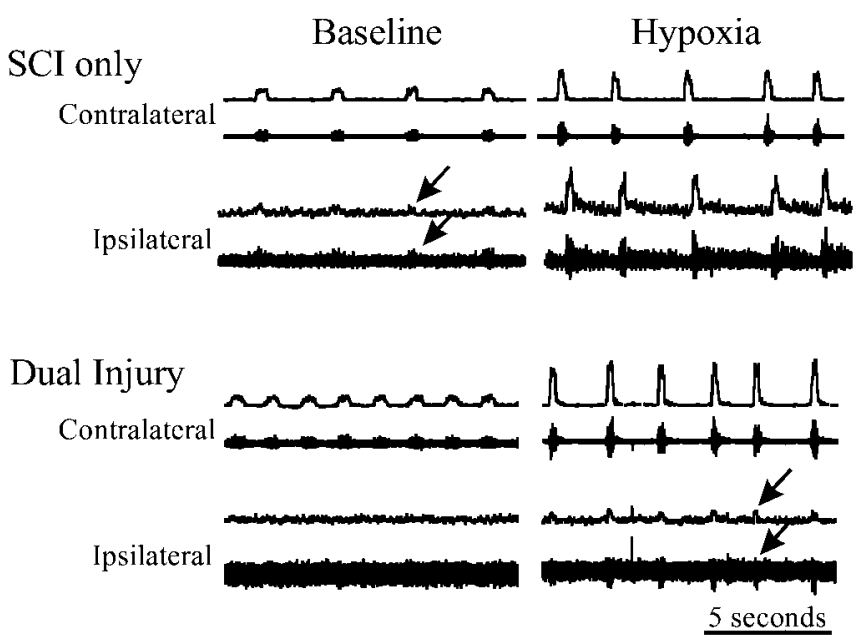

Figure 4. Representative contralateral and ipsilateral rectified and moving averaged (top traces) and raw (bottom traces) phrenic neurograms from $\mathrm{C}_{2}$ hemisected (SCl only) and combined $C_{2}$ injury and ipsilateral phrenicotomy (Dual Injury) rats. Measurements were obtained during baseline and hypoxic recording conditions. The time scale is identical for all traces. The voltage scale for all contralateral phrenic neurograms also is identical between rats. The voltage scale for the ipsilateral phrenic neurograms is increased by a factor of 10 compared with the contralateral side. Notice the absence of crossed phrenic activity in the dual injury rat. In addition, notice the higher baseline and hypoxic burst frequency, and the greater change in contralateral phrenic neurogram amplitude, in the dual injury rat compared with $\mathrm{SCl}$ alone. Arrows indicate an example of crossed phrenic motor activity.
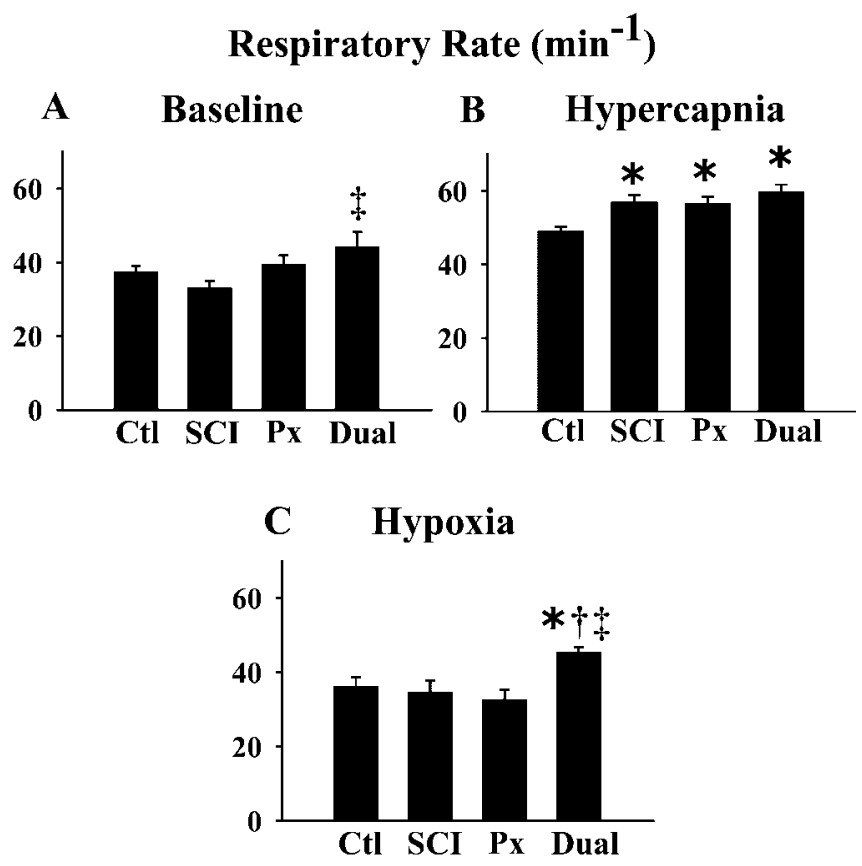

Figure 5. Burst frequency (i.e., respiratory rate) obtained from the contralateral phrenic nerve from control $(C t l), C_{2}$ injured $(S C l)$, phrenicotomy $(P x)$, and combined $C_{2}$ injury and ipsilateral phrenicotomy (Dual) groups. Measurements were taken during baseline, hypercapnic, and hypoxic recording conditions. ${ }^{*} p<0.05$ relative to controls; ${ }^{\dagger} p<0.05$ relative to phrenicotomy alone; ${ }^{\ddagger} p<0.05$ relative to $C_{2}$ hemisection alone.

of the decrementing nature of the rate response during that challenge.

\section{Discussion}

This investigation has provided novel perspectives about the functional role of respiratory motor recovery after unilateral cer- vical SCI. First, we have demonstrated that crossed phrenic activity facilitates the generation of large inspiratory volumes in anesthetized rats. These data provide essential baseline information for future studies assessing novel therapeutic strategies designed to strengthen this motor recovery. Second, by preventing relay of this motor recovery, we were able to reveal additional functional plasticity in contralateral respiratory motor output. These results suggest a compensatory response to the loss of motor recovery and provide insight into mechanisms of respiratory control via a high cervical SCI paradigm.

\section{Functional phrenic motor recovery}

Phrenicotomy in $\mathrm{C}_{2}$ injured rats prevented CPP-associated phrenic motor output from reaching the diaphragm. During conditions resulting in large inspiratory volumes, tidal volume in the dual injury group was lower than $\mathrm{C}_{2}$ injury alone. Indeed, the effect of dual injury on volume was greater during sighs than after vagotomy (Fig. 2) and may reflect the larger tidal volumes generated during the former behavior (Table 2). It follows that the CPP mediates sufficient respiratory drive to have significant functional benefit, albeit at a reduced level of output. After unilateral diaphragm paralysis (i.e., after $\mathrm{C}_{2}$ hemisection), the affected diaphragm moves rostral during inspiration (Takeda et al., 1995). Low amplitude crossed phrenic activity could restrict rostral movement during inspiration, thereby improving pulmonary mechanics.

\section{Compensation from other respiratory motoneurons}

$\mathrm{C}_{2}$ hemisection interrupts bulbospinal drive to all respiratory muscles distal to the lesion (e.g., ipsilateral diaphragm; intercostals), whereas by its nature unilateral phrenicotomy produces a more selective deficit. Despite these differences, the effect of each injury alone on the breathing pattern was similar. This suggests greater recruitment of other respiratory muscles in $\mathrm{C}_{2}$ injured rats to maintain inspiratory volume. Although such recruitment has not been investigated after these injuries, it does occur after muscle weakness (Farquhar et al., 1986) and increased respiratory drive (Cooke et al., 1993). Tidal volume was decreased in phrenicotomized rats when subjected to $\mathrm{C}_{2}$ hemisection. This is consistent with the fact that chest wall muscles are recruited after unilateral paralysis of the diaphragm.

Altered vagal feedback has been implicated in the rapid shallow breathing after $\mathrm{C}_{2}$ hemisection (Golder et al., 2001b). This breathing pattern also exists in phrenicotomized rats at $8 \mathrm{~d}$ after injury (Rocco et al., 1997). The effects of unilateral phrenicotomy at 2 months after injury and the role of altered vagal feedback are novel findings. The stimulus for altered vagal feedback is unknown but may include changes in pulmonary or chest wall compliance (Rocco et al., 1997) or primary lung disease.

Interestingly, the pattern of breathing in $\mathrm{C}_{2}$ injured rats before vagotomy was not altered by ipsilateral phrenicotomy. It is unlikely that the ipsilateral phrenic nerve was quiescent before vagotomy because crossed phrenic activity has been observed during similar conditions (Nantwi et al., 1999). Instead, recruitment of other respiratory muscles may have completely compensated for the loss of crossed phrenic activity before vagotomy. However, when large tidal volumes were required (e.g., sighs), such compensation was not adequate to maintain inspiratory motor activity. Thus, we investigated the potential for compensatory plasticity in contralateral motoneurons by recording phrenic neurograms during various chemical challenges. 


\section{Increased contralateral phrenic motor output}

Unilateral SCI decreases contralateral phrenic neurogram amplitudes during hypercapnia (Golder et al., 2001a). The onset of this contralateral phrenic motor plasticity was coincident with spontaneous motor recovery in the ipsilateral phrenic nerve, suggesting that a causal relationship may exist between the two events. Interestingly, when the ipsilateral phrenic nerve of $\mathrm{C}_{2}$ injured rats was sectioned, this contralateral change in phrenic function was not expressed. Instead, contralateral phrenic neurogram amplitudes were elevated above control and single injury rats regardless of the challenge studied. These results support the hypothesis that contralateral respiratory motoneurons are recruited and increase their discharge rate to compensate for loss of crossed phrenic activity in the dual injury paradigm. In addition, contralateral phrenic motor output in the dual injury group was increased during mechanical ventilation and while chemical drive was standardized, suggesting that these changes represent a long-lasting form of motor plasticity. If these changes were only a reflex recruitment of motoneuron pools, then presumably they would be reversed if the motor deficit were removed (i.e., in these experiments via mechanical ventilation).

Segmental mechanisms for increased contralateral phrenic neurogram amplitude include increased recruitment of motoneurons and increased conduction velocity along the nerve. Strength training has been shown to increase the number of motor units recruited for a given task, increase maximal motor unit discharge rate, and increase neural conduction velocity (Patten and Kamen, 2000; Ross et al., 2001; Patten et al., 2001). The effects of training on phrenic motoneurons are unknown. Nevertheless, it is tempting to consider that phrenic motor units may respond to increased activity in a manner similar to that of other skeletal muscles. If so, the results from this study may reflect a form of activity-dependent plasticity.

\section{Altered supraspinal control of breathing}

In addition to segmental mechanisms, increased contralateral phrenic motor output may occur after physiological and functional reorganization in supraspinal respiratory premotor neurons. In that context, it is noteworthy that phrenicotomy modulated the effects of $\mathrm{C}_{2}$ injury on phrenic burst frequency. Previously, we reported that burst frequency decreased during baseline conditions and was elevated during chemoreceptor challenge in $C_{2}$ injured rats (Golder et al., 2001a). In the current study, burst frequency was elevated above controls during hypercapnia after SCI alone. However, frequency was not altered during hypoxia, which may reflect the poikilocapnic nature of this stimulus. SCI may induce plasticity in the supraspinal control of breathing via axotomy of bulbospinal projections of premotor neurons and respiratory-related raphé neurons (Manaker et al., 1992; Bernstein-Goral et al., 1997; Chen and Tseng, 1997; Jain et al., 2000; Wang et al., 2000), damage to ascending spinobulbar projections (Hubscher and Johnson, 1999), or interruption of afferents segmentally via cervical dorsal rhizotomy. In the current study, unilateral phrenicotomy also increased burst frequency during hypercapnia, suggesting that this effect of $\mathrm{C}_{2}$ hemisection may occur via injury to ascending spinobulbar projections of phrenic afferents.

In the rat, the role of phrenic afferents on supraspinal respiratory neurons remains unknown. However, stimulation of these fibers alters c-Fos expression in neurons located in regions of the brainstem associated with respiratory pattern generation (Malakhova and Davenport, 2001). In addition, acute phrenicotomy alters the respiratory rate response to hypoxia in anesthetized rats
(Bach and Mitchell, 2000). Interestingly, ipsilateral phrenicotomy increased baseline burst frequency in $C_{2}$ injured rats, suggesting that an inhibitory element had been removed.

\section{Phrenicotomy alters crossed phrenic activity}

Ipsilateral phrenicotomy also modulated $\mathrm{C}_{2}$ injury-induced motor plasticity in the ipsilateral phrenic nerve. In this study, crossed phrenic activity was absent during baseline conditions in all rats with dual injury. The mechanisms whereby phrenicotomy suppresses the CPP are unknown. Liou and Goshgarian (1994) investigated acute $C_{2}$ injuries in chronically phrenicotomized rats and reported that the CPP was diminished in amplitude. The authors speculated that phrenicotomy may alter the $C_{2}$ injuryinduced structural and synaptic plasticity that is believed to favor synaptic efficacy of decussating bulbospinal pathways (Sperry and Goshgarian, 1993). Shortly after $\mathrm{C}_{2}$ hemisection, astrocytes retract from motoneurons, and the size and number of synaptic inputs increase (Goshgarian et al., 1989; Sperry and Goshgarian, 1993). In contrast, axotomy produces opposite effects, including stacking of astrocytic processes around motoneurons (for review, see Aldskogius and Kozlova, 1998). Such reactive deafferentation strips motoneurons of synaptic contact. Similar effects have been observed after phrenicotomy in rats (Gould and Goshgarian, 1997; Liou and Goshgarian, 1997). In addition to structural plasticity, peripheral nerve injury alters electrophysiological characteristics of the axotomized motoneurons (for review, see Titmus and Faber, 1990). These effects include a progressive decline in axon diameter and conduction velocity. The effects of phrenicotomy on phrenic neurograms have been assessed in rats up to 4 weeks after injury (Liou and Goshgarian, 1994). Electrically evoked potentials were decreased and latency increased in the proximal stump of the injured phrenic nerve, suggesting decreased conduction velocity. Collectively, these effects of axotomy could explain the low amplitude phrenic neurograms observed after phrenicotomy alone and the absence of crossed phrenic activity in the dual injury group.

\section{Phrenic function and SCI modeling}

There has been growing interest in the use of cervical SCI models to test experimental interventions for promoting spinal cord repair (Onifer et al., 1997; Diener and Bregman, 1998; Liu et al., 1999; Reier et al., 2002). Aside from clinical relevancy, these models offer a range of sophisticated outcome measures related to motor, sensory, and autonomic consequences of SCI. The phrenic motor system is especially intriguing because of its inherent plasticity, as well as its capacity for providing useful indices of therapeutic safety and efficacy. The findings reported here, coupled with previous reports from this (Nantwi et al., 1999; Golder et al., 2001a,b) and other laboratories (Teng et al., 1999), are beginning to provide further delineation of phrenic motor responses to SCI that complements the base of knowledge related to the well characterized CPP.

\section{References}

Aldskogius H, Kozlova EN (1998) Central neuron-glial and glial-glial interactions following axon injury. Prog Neurobiol 55:1-26.

Bach KB, Mitchell GS (2000) Effects of phrenicotomy and exercise on hypoxia-induced changes in phrenic motor output. J Appl Physiol 89:1884-1891.

Bernstein-Goral H, Diener PS, Bregman BS (1997) Regenerating and sprouting axons differ in their requirements for growth after injury. Exp Neurol 148:51-72.

Chen JR, Tseng GF (1997) Membrane properties and inhibitory connec- 
tions of normal and upper cervically axotomized rubrospinal neurons in the rat. Neuroscience 79:449-462.

Cherniack NS, von Euler C, Glogowska M, Homma I (1981) Characteristics and rate of occurrence of spontaneous and provoked augmented breaths. Acta Physiol Scand 111:349-360.

Cooke IR, Soust M, Berger PJ (1993) Differential recruitment of inspiratory muscles in response to chemical drive. Respir Physiol 92:167-181.

Diener PS, Bregman BS (1998) Fetal spinal cord transplants support the development of target reaching and coordinated postural adjustments after neonatal cervical spinal cord injury. J Neurosci 18:763-778.

Farquhar R, Leslie GC, Part NJ (1986) How is ventilation maintained in the presence of the muscle relaxant, dantrolene sodium? A study in the anaesthetized rat. Br J Pharmacol 88:79-86.

Golder FJ, Reier PJ, Bolser DC (2001a) Altered respiratory motor drive after spinal cord injury: supraspinal and bilateral effects of a unilateral lesion. J Neurosci 21:8680-8689.

Golder FJ, Reier PJ, Davenport PW, Bolser DC (2001b) Cervical spinal cord injury alters the pattern of breathing in anesthetized rats. J Appl Physiol 91:2451-2458.

Golder FJ, Davenport PW, Johnson RD, Reier PJ, Bolser DC (2002) C2 spinal hemisection. (C2HS) and unilateral phrenicotomy (Px) have a similar effect on the breathing pattern. FASEB J 16:A67.

Goshgarian HG (1979) Developmental plasticity in the respiratory pathway of the adult rat. Exp Neurol 66:547-555.

Goshgarian HG (1981) The role of cervical afferent nerve fiber inhibition of the crossed phrenic phenomenon. Exp Neurol 72:211-225.

Goshgarian HG, Yu XJ, Rafols JA (1989) Neuronal and glial changes in the rat phrenic nucleus occurring within hours after spinal cord injury. J Comp Neurol 284:519-533.

Goshgarian HG, Ellenberger HH, Feldman JL (1991) Decussation of bulbospinal respiratory axons at the level of the phrenic nuclei in adult rats: a possible substrate for the crossed phrenic phenomenon. Exp Neurol 111:135-139.

Gould DJ, Goshgarian HG (1997) Glial changes in the phrenic nucleus following superimposed cervical spinal cord hemisection and peripheral chronic phrenicotomy injuries in adult rats. Exp Neurol 148:1-9.

Hubscher CH, Johnson RD (1999) Effects of acute and chronic midthoracic spinal cord injury on neural circuits for male sexual function. I. Ascending pathways. J Neurophysiol 82:1381-1389.

Jain N, Florence SL, Qi Hx, Kaas JH (2000) Growth of new brainstem connections in the adult monkey with massive sensory loss. Proc Natl Acad Sci USA 97:5546-5550.

Liou WW, Goshgarian HG (1994) Quantitative assessment of the effect of chronic phrenicotomy on the induction of the crossed phrenic phenomenon. Exp Neurol 127:145-153.

Liou WW, Goshgarian HG (1997) The superimposed effects of chronic phrenicotomy and cervical spinal cord hemisection on synaptic cytoarchitecture in the rat phrenic nucleus. Exp Neurol 145:258-267.

Lipski J, Zhang X, Kruszewska B, Kanjhan R (1994) Morphological study of long axon projections of ventral medullary inspiratory neurons in the rat. Brain Res 640:171-184.

Liu Y, Kim D, Himes BT, Chow SY, Schallert T, Murray M, Tessler A, Fischer I (1999) Transplants of fibroblasts genetically modified to express BDNF promote regeneration of adult rat rubrospinal axons and recovery of forelimb function. J Neurosci 19:4370-4387.

Malakhova OE, Davenport PW (2001) c-Fos expression in the central nervous system elicited by phrenic nerve stimulation. J Appl Physiol 90:1291-1298.
Manaker S, Tischler LJ, Morrison AR (1992) Raphespinal and reticulospinal axon collaterals to the hypoglossal nucleus in the rat. J Comp Neurol 322:68-78.

Muir GD, Katz SL, Gosline JM, Steeves JD (1998) Asymmetric bipedal locomotion: an adaptive response to incomplete spinal injury in the chick. Exp Brain Res 122:275-282.

Nantwi KD, El-Bohy A, Goshgarian HG (1996) Actions of systemic theophylline on hemidiaphragmatic recovery in rats following cervical spinal cord hemisection. Exp Neurol 140:53-59.

Nantwi KD, El-Bohy AA, Schrimsher GW, Reier PJ, Goshgarian HG (1999) Spontaneous recovery in a paralyzed hemidiaphragm following upper cervical spinal cord injury in adult rats. Neurorehab Neural Repair 13:225-234.

Onifer SM, Rodriguez JF, Santiago DI, Beneitez JC, Kim DT, Brunschwig JPR, Pacheco JT, Perrone JV, Llorente O, Hesse DH, Martinez-Arizalla A (1997) Cervical spinal cord injury in the adult rat: assessment of forelimb dysfunction. Restor Neurol Neurosci 11:211-223.

Patten C, Kamen G (2000) Adaptations in motor unit discharge activity with force control training in young and older human adults. Eur J Appl Physiol 83:128-143.

Patten C, Kamen G, Rowland DM (2001) Adaptations in maximal motor unit discharge rate to strength training in young and older adults. Muscle Nerve 24:542-550.

Reier PJ, Golder FJ, Bolser DC, Hubscher C, Johnson R, Schrimsher GW, Velardo MJ (2002) Gray matter repair in the cervical spinal cord. In: Spinal cord trauma: regeneration, neural repair and functional recovery (McKerracher L, Doucet G, Rossignol S, eds), pp 49-70. New York: Elsevier.

Rocco PR, Faffe DS, Feijoo M, Menezes SL, Vasconcellos FP, Zin WA (1997) Effects of uni- and bilateral phrenicotomy on active and passive respiratory mechanics in rats. Respir Physiol 110:9-18.

Ross A, Leveritt M, Riek S (2001) Neural influences on sprint running: training adaptations and acute responses. Sports Med 31:409-425.

St. John WM, Paton JFR (2000) Characterizations of eupnea, apneusis and gasping in a perfused rat preparation. Respir Physiol 123:201-213.

Sperry M, Goshgarian HG (1993) Ultrastructural changes in the rat phrenic nucleus developing within $2 \mathrm{~h}$ after cervical spinal hemisection. Exp Neurol 120:233-244.

Takeda S, Nakahara K, Fujii Y, Matsumura A, Minami M, Matsuda H (1995) Effects of diaphragmatic plication on respiratory mechanics in dogs with unilateral and bilateral phrenic nerve paralyses. Chest 107:798-804.

Teng YD, Mocchetti I, Taveira-DaSilva AM, Gillis RA, Wrathall JR (1999) Basic fibroblast growth factor increases long-term survival of spinal motor neurons and improves respiratory function after experimental spinal cord injury. J Neurosci 19:7037-7047.

Titmus MJ, Faber DS (1990) Axotomy-induced alterations in the electrophysiological characteristics of neurons. Prog Neurobiol 35:1-55.

Wang YJ, Ho HW, Tseng GF (2000) Fate of the supraspinal collaterals of cord-projection neurons following upper spinal axonal injury. J Neurotrauma 17:231-241.

Webb AA, Muir GD (2002) Compensatory locomotor adjustments of rats with cervical or thoracic spinal cord hemisections. J Neurotrauma 19:239-256.

Vidruk EH, Olson EB Jr, Ling L, Mitchell GS (2001) Responses of singleunit carotid body chemoreceptors in adult rats. J Physiol 531:165-170.

Zhou SY, Goshgarian HG (2000) 5-Hydroxytryptophan-induced respiratory recovery after cervical spinal cord hemisection in rats. J Appl Physiol 89:1528-1536. 